\title{
LA CONSTITUCIONALIZACIÓN DE LOS DERECHOS DE LOS CONSUMIDORES CON ESPECIAL REFERENCIA AL ORDENAMIENTO JURÍDICO CHILENO
}

Erika M. Isler Soto

THE CONSTITUTIONALIZATION OF THE CONSUMER RIGHTS WITH SPECIAL REFERENCE TO THE CHILEAN LEGAL SYSTEM

\section{RESUMEN}

EL PRESENTE DOCUMENTO SE REFIERE AL FENÓMENO DE LA CONSTITUCIONALIZACIÓN DE LOS DERECHOS DE LOS CONSUMIDORES. CON TAL OBJETO, SE COMIENZA EXPONIENDO EL GRADO DE RECONOCIMIENTO QUE EXISTE EN CONSTITUCIONES COMPARADAS DE LAS garantías de LOS usuarios. Posteriormente, SE REVISA EL SISTEMA CONSTITUCIONAL CHILENO Y SE SOSTIENE QUE DE SUS DISPOSICIONES SII ES POSIBLE INFERIR LA PROTECCIÓN DEL SUJETO MÁS DÉBIL DE LA RELACIÓN DE CONSUMO, AÚN CUANDO NO SE LO MENCIONE DE MANERA EXPRESA. EN EL MISMO SENTIDO, SE CITAN LAS PROPUESTAS DE REFORMA CONSTITUCIONAL QUE HAN EXISTIDO EN NUESTRO PAÍS AL RESPECTO.

PALABRAS CLAVE

CONSUmidor; Constitución; Derechos Humanos.

\section{ABSTRACT}

THIS DOCUMENT REFERS TO THE CONSTITUTIONALIZATION OF THE CONSUMER RIGHTS. TO THIS END, THE PAPER STARTS EXPOSING THE COMPARATIVE EXPERIENCE AT THE PRESENT. AFTER THAT, THE DOCUMENT REFERS SPECIALLY TO THE CHILEAN CONSTITUTIONAL SYSTEM, IN WHICH OPPORTUNITY WE ESTIMATE, THAT FROM ITS RULES, IT IS POSSIBLE TO INFER THE PROTECTION OF THE CONSUMER RIGHTS, EVEN IF IT IS NOT SPECIFICALLY MENTIONED. FINALLY, THE PAPER REFERS TO SOME CONSTITUTIONAL REFORM PROPOSALS IN CHILE.

KEYWORDS

CONSUMER; CONSTITUtion; Human Rights.

\section{INTRODUCCIÓN}

De un tiempo a esta parte, se ha advertido la generación de un proceso que la doctrina ha denominado "constitucionalización de los derechos", y que consiste, según Guastini, en la "transformación de un ordenamiento al término del cual [...] [este] resulta totalmente 'impregnado' por las normas constitucionales” (2003, p. 49). ${ }^{1}$ Ahora bien, la recepción de esta técnica no suele ser absoluta, sino que, por el contrario, un sistema normativo puede encontrarse más o menos constitucionalizado ${ }^{2}$ según el cumplimiento de sus condiciones. ${ }^{3}$

Una de las consecuencias que ha traído el fenómeno señalado es precisamente el reconocimiento, en las Cartas Fundamentales, de materias antes destinadas únicamente 
a la regulación legal. Las Constituciones se tornan entonces más extensas y se alteran los principios del Derecho Constitucional Clásico, que se hacía cargo únicamente de la actividad estatal. ${ }^{4}$

Tal es lo que ha ocurrido con los derechos de los consumidores, en el sentido de que los ordenamientos jurídicos modernos — luego de haber regulado estas materias mediante leyes - han optado por otorgarles una tutela jerárquicamente superior.

Lo anterior ha conllevado que, desde la perspectiva dogmática, se introduzca una nueva interrogante en torno a la adscripción del Derecho del Consumidor a una rama jurídica específica: si ya es poco clara su naturaleza privada, pública, civil, económica o comercial, ahora se agrega una dimensión constitucional, lo que haría pensar que más bien se trata de un área autónoma de protección.

La Constitución Política chilena, por su parte, no contempla reconocimiento expreso alguno de los derechos de los consumidores; en consecuencia, surge la siguiente pregunta: ¿es necesaria y — más aún, conveniente_- la consagración constitucional de sus derechos, o, por el contrario, bastará con la protección legal y administrativa con la que cuentan actualmente?

El presente trabajo, pues, tiene por objeto otorgar al lector un panorama acerca del estado actual de esta problemática en el Derecho Comparado, así como proponer el nivel de reconocimiento de los derechos de los consumidores que existe en nuestra Carta Fundamental.

\section{LOS DERECHOS DE LOS CONSUMIDORES EN SISTEMAS CONSTITUCIONALES COMPARADOS}

Tal como se ha adelantado, es cada vez mayor el número de constituciones que han optado por reconocer los derechos de los consumidores. A este respecto, puede advertirse la utilización de dos técnicas por parte del poder constituyente, a saber: incorporar nuevas garantías en los catálogos de derechos fundamentales o reconocer al grupo tutelado a propósito del sistema económico.

\section{I RECONOCIMIENTO DE LOS DERECHOS DE LOS CONSUMIDORES, DENTRO DE LOS CATÁLOGOS DE DERECHOS HUMANOS}

La mayoría de las constituciones modernas han optado por reconocer la protección del consumidor en su parte dogmática, ${ }^{5}$ esto es, a propósito de los derechos del hombre.

A este respecto, cabe recordar que la consagración de los derechos fundamentales se ha realizado de manera gradual en el transcurso de la historia. En efecto, si bien el constitucionalismo clásico reconocía únicamente los derechos de primera generación -Derechos Civiles y Políticos_ ${ }^{6}$, con posterioridad se agregaron a ellos otras garantías, calificadas como de segunda generación —Derechos Sociales, Económicos y Culturales_ ${ }^{7}$ y de tercera generación — Derechos de los Pueblos o de la Solidaridad_ 8 . 
Y es precisamente a propósito de estas últimas que comienzan a tutelarse bienes jurídicos vinculados a intereses difusos o de sectores sociales infraprotegidos, entre los cuales se encuentran las garantías concedidas a los consumidores (CEA EGAÑA, 2004, p. 64). ${ }^{9}$

En este sentido se ha señalado:

Paralelamente a la agenda de los derechos humanos, se expandió el temario de protección de otros valores comunes, tales como la protección del medio ambiente, y crecieron o aparecieron nuevas preocupaciones ciudadanas en torno a las cuales se formaron organizaciones y alianzas, como los movimientos de defensa de los consumidores [...]. Al mismo tiempo, se fueron reconociendo los puntos de contacto entre esas áreas y el campo de los derechos humanos (MEDINA; ZALAQUETT, 2008, p. 11).

Ahora bien, en la materia que nos ocupa — a diferencia de los derechos de primera generación — no se pretende tutelar al sujeto de los abusos que se pudieren derivar del actuar del Estado — salvo, claro está, que este actúe como proveedor —, sino de aquellos derivados de otras personas o entidades de carácter privado igual que él, pero que pudieren incurrir en prácticas comerciales leoninas.

Lo anterior ha sufrido una fuerte influencia de una tendencia a la internacionalización de los derechos fundamentales que ha ido transformando el Derecho Constitucional y cuyo rasgo característico consiste en la recepción de instrumentos y declaraciones internacionales, que pasan a integrar los ordenamientos jurídicos internos o bien inspiran modificaciones normativas. ${ }^{10}$ A modo de ejemplo, cabe señalar que en el año 2000, los países integrantes del Mercosur — que, en general, coinciden con aquellos que han tutelado al usuario con rango constitucional- , suscribieron un documento denominado "Declaración Presidencial de Derechos Fundamentales de los Consumidores del Mercosur”, el cual consagra — entre otras — las garantías de los consumidores. ${ }^{11}$

Ahora bien, dentro de las cartas fundamentales que han optado por esta técnica, encontramos la Constitución Política de la Nación Argentina, cuyo texto actual, además de mencionar a los consumidores como un grupo especialmente tutelado, les garantiza los derechos que son calificados como "básicos": ${ }^{12}$ a la salud, la seguridad, la educación, la información y la libertad de elección. De manera adicional, establece la tutela de sus intereses económicos, la defensa de la competencia y el control de los monopolios naturales y legales, además de las garantías a la calidad, la eficiencia y la asociación. ${ }^{13}$ Por último, y con el objeto de hacer operativas las prerrogativas otorgadas, contempla una acción especial, de carácter popular, que puede ser ejercida en caso de que se transgreda cualquiera de los derechos señalados. ${ }^{14}$

Por otra parte, cabe destacar que el tenor literal de las disposiciones contempladas en la Carta Fundamental trasandina ha permitido que la doctrina considere la relación 
de consumo como criterio de aplicabilidad del Derecho del Consumidor, cuestión que antes era fuertemente discutida.

En un sentido bastante similar, la Constitución Política del Estado de Bolivia consagra las garantías en estudio, en sus capítulos segundo - "Derechos Fundamentalísimos" — y quinto — "Derechos sociales y económicos"_. ${ }^{15}$ Cabe tener presente, además, que este cuerpo normativo establece otras prerrogativas que han sido omitidas por las distintas legislaciones, tales como al "suministro de alimentos, fármacos y productos en general, en condiciones de inocuidad, calidad y cantidad disponible adecuada y suficiente, con prestación eficiente y oportuna del suministro"; así como al "acceso a un sistema de transporte integral en sus diversas modalidades", el cual debe además ser "eficiente y eficaz". 16

En este grupo encontramos también el ordenamiento jurídico ecuatoriano, cuya Carta Fundamental consagra en un acápite denominado "Derechos de las personas y grupos de atención prioritaria”, además de los derechos básicos a la libre elección y a la información, otras instituciones, tales como el derecho a la calidad en el consumo, a la libre asociación y la prohibición del engaño. ${ }^{17}$ Llama la atención, que también se establezca la responsabilidad patrimonial del Estado — de naturaleza subjetiva- en caso de que los servicios públicos generen daños a los usuarios.

La Constitución Política española en tanto, incluye en su título primero "De los Derechos y Deberes Fundamentales", un capítulo destinado a "Los principios rectores de la política social y económica”, en el cual, junto a los derechos básicos a la seguridad, la salud, la información y la educación, se establece la tutela de los legítimos intereses económicos de los usuarios. ${ }^{18}$

Por último, cabe mencionar dentro de este grupo, la Carta Fundamental brasileña, la cual, si bien en su Título segundo — "De los derechos y garantías fundamentales”_ consagra el deber del Estado de proteger al consumidor, encarga su regulación al poder legislativo. ${ }^{19}$

\section{I.2 ReCONOCIMIENTO DE LOS DERECHOS DE LOS CONSUMIDORES, A PROPÓSITO DEL SISTEMA ECONÓMICO}

Otros constituyentes han optado por proteger al consumidor a propósito de las normas que regulan el sistema económico interno, razón por la cual se ha planteado que las normas propias del Derecho del Consumidor no solo son de orden público, sino que en realidad integran el denominado Orden Público Económico, entendido como: "Conjunto de principios y normas jurídicas que organizan la economía de un país y facultan a la autoridad para regularla de acuerdo con los valores de la sociedad nacional articulados en la Constitución” (CEA EGAÑA, 2004, p. 463).

Encontramos en este grupo la Constitución peruana, la cual establece la tutela del consumidor en su Título III — “Del régimen económico”- y cuyas garantías — a la información, la salud, la seguridad—- son de cargo del Estado. ${ }^{20}$ 
Un segundo ejemplo lo encontramos en la Constitución portuguesa, cuya Parte Segunda - "Organización Económica”- establece tanto los derechos de los consumidores como la obligación del Estado de satisfacerlos. Adicionalmente, consagra otros deberes, tales como promover el bienestar social - principalmente, de los sujetos vulnerables - y asegurar el funcionamiento eficiente de los mercados. ${ }^{21}$

\section{Dos PROPUESTAS DE REFORMA CONSTITUCIONAL}

La Carta Fundamental chilena - tal como se ha adelantado - no menciona de manera expresa a los consumidores como un grupo vulnerable que merezca tutela especial.

De acuerdo con el profesor Cea, la exclusión de algunos derechos del catálogo de garantías fundamentales consagrado por nuestra Constitución tendría una justificación: el Poder Constituyente nacional "privilegia, como principio general, los derechos individuales sobre los sociales y, más todavía, los sitúa por encima de los derechos de la tercera generación, desconocidos por él" (CEA EGAÑA apud PEÑA GONZÁLEZ, 1996, p. 57). De acuerdo a lo anterior es que habrían quedado marginados otro grupo de atributos, entre los cuales se encuentran precisamente "instituciones rectoras e intereses infra o subprotegidos", tales como los consumidores (idem).

La advertencia de esta situación ha motivado la propuesta de algunas iniciativas parlamentarias que han buscado salvar esta omisión, las cuales se pasan a enunciar.

La primera de ellas la presentaron, en el año 2002, los diputados Burgos, Saffirio, Silva, Tuma, Ascencio y Mella. ${ }^{22}$ Esta moción, fundamentada en consideraciones de índole económica, propuso la protección constitucional no solo de los derechos de los consumidores, sino también de la libre competencia. De acuerdo a lo anterior es que dicha consagración debía ubicarse a propósito de las garantías de los individuos, esto es, en la parte dogmática.

En concreto, el proyecto propuso en primer lugar la modificación del tenor del Art. $19 \mathrm{~N}^{\circ} 22$ inc. $1^{\circ} \mathrm{CPR}$, el cual — de acuerdo a la nueva redacción - consagraría el derecho a "la no discriminación arbitraria en el trato que deben dar el Estado y sus organismos en materia económica y la defensa de la libre competencia”. En este caso, vemos que se buscaba proteger a los gobernados no de los proveedores privados, sino del propio Estado.

En segundo lugar, se propuso incorporar un nuevo número - $\mathrm{N}^{\circ} 27-$ al Art. 19 $\mathrm{CPR}$, el cual aseguraría a todas las personas: "[El] derecho de los consumidores y usuarios a la calidad de los bienes y servicios consumidos, a la protección de su salud, seguridad e intereses económicos, a la reparación de los daños sufridos, así como a promover su derecho a la información, a la educación y a organizarse para salvaguardar sus intereses $[\ldots]$ ".

De acuerdo a lo anterior es que la iniciativa así presentada buscaba tutelar los derechos básicos de los consumidores —a la salud, la seguridad, la indemnización, 
la información, la educación_- además de consagrar otras garantías, tales como la calidad, la protección de sus intereses económicos y la libre asociación, a la manera de algunas legislaciones comparadas. No obstante lo anterior, esta iniciativa no tuvo el éxito esperado y actualmente se encuentra archivada.

Más recientemente, el 5 de abril del año 2011, los senadores Espina, Chadwick, García, Tuma — nuevamente - y Zaldívar presentaron en la Cámara Alta un nuevo proyecto, ${ }^{23}$ que buscaba proteger directamente al consumidor, sin relacionarlo con la libre competencia, tutela que debía consagrarse a propósito del derecho a la libertad económica del individuo.

De esta manera, se pretendía incorporar al inciso primero del Art. $19 \mathrm{~N}^{\circ} 21 \mathrm{CPR}^{24}$ la siguiente expresión: "Es deber del Estado fomentar la protección de los derechos de los consumidores, la libre elección de los bienes y servicios, una información suficiente, veraz y oportuna, como su derecho a no ser discriminados arbitrariamente y a ser reparados de los daños sufridos, en conformidad a la ley”.

Vemos que esta vez, si bien se propone consagrar similares derechos a la iniciativa señalada con anterioridad, se pone de cargo del Estado el fomento de su protección. En cualquier caso, cabe señalar que este proyecto se encuentra actualmente en primer trámite constitucional.

\section{LOS DERECHOS DE LOS CONSUMIDORES EN LA}

\section{Constitución Política de la República de ig8o}

No obstante el panorama señalado con anterioridad, y siguiendo a Hesse: "[La] Constitución no es un sistema cerrado y omnicomprensivo; no contiene una codificación, sino un conjunto de principios concretos y elementos básicos del ordenamiento jurídico de la comunidad, para el que ofrece una norma marco. En este sentido, es un ordenamiento abierto" (2001, p. 6).

Desde este punto de vista, sí es posible advertir que, pese al aparente silencio del constituyente, es posible reconocer en el texto de nuestra Carta Fundamental manifestaciones de la tutela del sujeto más débil de la relación de consumo, ${ }^{25}$ las cuales se pasan a comentar.

\section{I Derecho del Consumidor y Estado Social y Democrático de Derecho}

Se entiende por Estado de Derecho a aquel que:

Consiste en la sujeción de la actividad estatal a la Constitución y a las normas aprobadas conforme a los procedimientos que ella establezca, que garantizan el funcionamiento responsable y controlado de los órganos del poder; el ejercicio de la autoridad conforme a disposiciones conocidas y no retroactivas en términos perjudiciales, y la observancia de los 
derechos individuales, sociales, culturales y políticos (VALADÉS, 2002, p. 219-291). ${ }^{26}$

Junto a esta institución, ha surgido el Estado Social y Democrático de Derecho, que, según la doctrina moderna, tiende a predominar en los regímenes públicos actuales. Según Valadés, se incluyen en este concepto: "La tutela del individuo y de sus derechos de participación política y las relaciones de clase, instituyendo mecanismos de distribución de riqueza a través del salario, del ejercicio de derechos colectivos y de un conjunto de prestaciones que atienden al bienestar" (idem). En el mismo sentido, continúa este autor señalando que "[lo] característico de esta forma de Estado es la vinculación entre los contenidos sociales y los concernientes al pluralismo" (idem).

Ahora bien, y en lo relativo a la materia que nos ocupa, Rodríguez Llamas ha sostenido que "la configuración del Estado como Estado social, que debe favorecer la calidad de vida de sus ciudadanos y el acceso de los mismos a determinados bienes en los que se refleja esa calidad de vida, explica la tendencia a la protección del más débil” (2002, p. 21).

Se trata de una consideración que, además, se vio reflejada en el mismo mensaje del proyecto de Ley que derivó en la Ley 19.496, el cual establecía que "[es] responsabilidad del Estado cautelar en forma especial los intereses de los grupos o sectores no organizados, entre los que se cuentan los consumidores". 27

En efecto, al igual que el Derecho Constitucional, el estatuto protector de los derechos de los consumidores busca proteger a un sujeto que es considerado vulnerable y cuya inferioridad frente al proveedor puede tener variados orígenes, a saber: la propiedad de los medios de producción, la superioridad económica, el carácter profesional del proveedor, la asimetría informativa existente entre los sujetos de la relación de consumo, etc.

Una manifestación de lo anterior la encontramos en el Art. 1 inc. $3^{\circ} \mathrm{CPR}$, según el cual el Estado está al servicio de la persona humana y su finalidad es promover el bien común, para lo cual debe contribuir a crear las condiciones necesarias con el objeto de favorecer la mayor realización espiritual y material que sea posible de los integrantes de la comunidad, entre los cuales se encuentran los consumidores. ${ }^{28}$

Esta declaración tendría su justificación, en el sentido de que la Constitución "[ordena] todas las esferas de la vida esenciales para la convivencia, precisamente porque dichas esferas son consustanciales a la vida del conjunto y se encuentran indisolublemente conectadas con el orden político" (2001, p. 5).

De la misma manera, el inciso 4 de la misma disposición establece como deber del Estado promover la integración armónica de todos los sectores de la Nación y asegurar el derecho de las personas a participar con igualdad de oportunidades en la vida nacional. ${ }^{29}$ 
De la lectura de las normas citadas es posible advertir que de las obligaciones del Estado referidas, particularmente las que tienen por objeto "crear las condiciones necesarias para la mayor realización” del ser humano, así como "promover la integración armónica de todos los sectores de la Nación y asegurar el derecho de las personas a participar con igualdad de oportunidades en la vida nacional", es posible derivar la protección de los consumidores, la cual precisamente busca permitir la realización del individuo y establecer mecanismos de equilibrio en las relaciones jurídicas, con fundamento en la justicia distributiva.

Por último, cabe destacar que, según el Art. 4 de nuestra Carta Fundamental, Chile es una República Democrática y, como tal:

Debe intervenir allí donde las situaciones de desigualdad y desequilibrio no pueden ser corregidas simplemente con el uso de medidas de tipo económico. Y es indudable que el 'derecho del consumidor' se anuda a una determinada situación de subordinación estructural y de necesidad abstracta de tutela (MOSSET ITURRASPE apud HUENCHIMAN, 2004, p. 58).

\subsection{RECONOCIMIENTO DE GARANTÍAS}

Tal como se ha adelantado, del texto de nuestra Carta Fundamental se desprende la tutela de los derechos de los consumidores, la cual, sin embargo, no se encuentra establecida en protección exclusiva de este grupo de sujetos, sino que busca el beneficio de todas las personas.

\section{2. i Derecho a la Seguridad en el CONSUMo}

Y AL MEDIO AMBIENTE LIBRE DE CONTAMINACIÓN

La LPC establece, en su Art. 3 letra d), el derecho a "la seguridad en el consumo de bienes o servicios, la protección de la salud y el medio ambiente”.

Se trata de una garantía de naturaleza extrapatrimonial que ya es posible reconocer en el catálogo de garantías contemplado en el Art. 19 CPR, particularmente a propósito de los derechos "a la vida y a la integridad física y psíquica de la persona" (Art. $19 \mathrm{~N}^{\circ} 1 \mathrm{CPR}$ ) y a "la protección de la salud" (Art. $19 \mathrm{~N}^{\circ} 9 \mathrm{CPR}$ ).

Por otra parte, la Ley 19.496 ha decidido, adicionalmente, tutelar el derecho a la protección del medio ambiente, el cual también se encuentra consagrado en la Carta Fundamental, particularmente en su Art. 19 No 8 CPR. Cabe señalar además, que el mismo numeral establece el deber del Estado de velar para que no se afecte esta garantía y se preserve la naturaleza, en cuya virtud faculta al legislador a "establecer restricciones específicas al ejercicio de determinados derechos o libertades", una de las cuales se encuentra constituida precisamente por el texto de la Ley $19.496 .{ }^{30}$ 


\subsubsection{DeRECho a LA NO Discriminación}

De acuerdo al Art. 3 letra c) LPC, le asiste al consumidor la garantía a "no ser discriminado arbitrariamente por parte de proveedores de bienes y servicios". Esta disposición se encuentra, además, complementada por el Art. 13 del mismo cuerpo legal, conforme al cual "[los] proveedores no podrán negar injustificadamente la venta de bienes o la prestación de servicios comprendidos en sus respectivos giros en las condiciones ofrecidas".

Ahora bien, desde el punto de vista meramente patrimonial, este derecho ha conllevado a que en materia de protección de los derechos de los consumidores - a diferencia del Derecho Común - la oferta sí obligue, de tal manera que, una vez que el consumidor ha decidido aceptar una propuesta realizada por un proveedor, no le sea lícito a este negarse a la celebración del contrato de consumo.

Respecto de esta garantía, Fernández Fredes señala: "[A] diferencia de otros de los derechos del consumidor, lo que con él se tutela no es un interés propiamente patrimonial, sino la dignidad esencial de la persona” (2003, p. 17).

A este respecto, cabe señalar que, en materia constitucional, las normas señaladas concretizan el principio de no discriminación, establecido en los Arts. 1 inc. $1^{\circ} \mathrm{CPR}^{31}$ y $19 \mathrm{~N}^{\circ} 2$ y $3 .{ }^{32}$ De la misma manera, su introducción en nuestro ordenamiento jurídico viene a dar cumplimiento a las obligaciones estatales de promover la integración armónica de todos los sectores de la nación y asegurar el derecho de las personas a participar con igualdad de oportunidades en la vida nacional (Art. 1 inc. $4^{\circ} \mathrm{CPR}$ ).

En razón de lo anterior es que el profesor Fernández ha señalado que, frente a la vulneración de esta garantía, no solo resultan procedentes las acciones derivadas de la LPC, sino que también podría dar lugar a la interposición de un recurso de protección (2003, p. 17).

\subsubsection{Derecho a la educación en el consumo}

Conforme al Art. 3 letra f) LPC, le asiste al consumidor el derecho a "la educación para un consumo responsable", el cual constituye una manifestación de la garantía constitucional consagrada en el Art. $19 \mathrm{~N}^{\circ} 10 \mathrm{CPR}$.

Ahora bien, el primer sujeto pasivo de la obligación de educar — de acuerdo a la misma disposición - es precisamente el Estado, ${ }^{33}$ el cual, por medio de su Institucionalidad - entre nosotros, el Servicio Nacional del Consumidor - diseña, promueve y realiza políticas públicas tendientes a elevar el nivel de la cultura del consumo nacional. ${ }^{34}$

Lo anterior en ningún caso exime al proveedor de dar cumplimiento a sus deberes de información establecidos en la Ley 19.496, ni tampoco merma el deber de los consumidores de informarse responsablemente (Art. 3 letra b LPC), tal como advierte Perret: "El consumidor es el actor principal que debe aprender a defenderse por sí mismo. [...] Esta educación no es solamente responsabilidad de las agencias 
estatales o privadas, sino que también es responsabilidad de la escuela, de la familia y de la sociedad en general" (1999, p. 23).

\subsubsection{Derecho a resarcimiento}

De acuerdo al Art. 3 letra e) LPC, le asiste al consumidor el derecho a "la reparación e indemnización adecuada y oportuna de todos los daños materiales y morales en caso de incumplimiento de cualquiera de las obligaciones contraídas por el proveedor". Se trata de una prerrogativa que encuentra fundamento en la protección constitucional de la propiedad, establecida en el Art. $19 \mathrm{~N}^{\circ} 24$ CPR. 35

Por otra parte, la jurisprudencia que se ha dictado en sede de protección de los derechos de los consumidores ha justificado la indemnización del daño moral - cuyo resarcimiento ha sido expresamente establecido por la LPC_-36 en razón de los derechos a la vida y a la integridad consagrados en el Art. $19 \mathrm{~N}^{\circ} 1 \mathrm{CPR}$.

En este sentido se pronunció el Segundo Juzgado de Policía Local de San Bernardo - confirmado por la Corte de Apelaciones de San Miguel_-, el cual, a propósito de los daños producidos por un error de rotulación en el suplemento alimenticio ADN, señaló que:

[...] el artículo $19 \mathrm{~N}^{\circ} 1$ de la Constitución Política de la República asegura a todas las personas el derecho a la vida y a la integridad física y psíquica, lo que significa que está elevado a la categoría constitucional el derecho de la persona a mantener su integridad psíquica y, por lo tanto, para el ordenamiento jurídico representa un interés que debe ser protegido, de manera que cualquiera acción desplegada por persona o agente alguno que provoque o atente esta integridad, constituye un perjuicio y por ende, un daño que el derecho debe restablecer, sea efectiva o alternativamente. ${ }^{37}$

\subsubsection{El DERECHO DE ASOCIACión}

Se entiende por derecho de asociación: "La libertad de todos los habitantes para conformar, por sí mismos o con otras personas, entidades que tengan una personalidad jurídica distinta de la de sus integrantes" (CARBONELL, 2006, p. 829).

Nuestra LPC no consagra de manera expresa esta garantía, omisión que, de acuerdo con Fernández Fredes, tendría justificación: "No se estimó necesario explicitarlo específicamente en la Ley $\mathrm{N}^{\circ} 19.496$, por ser una simple proyección a este campo concreto de la libertad de asociación consagrada por el $\mathrm{N}^{\circ} 15$ del artículo 19 de la Constitución Política" (1998, p. 118), esto es, "el derecho de asociarse sin permiso previo".

En efecto, la LPC, si bien no establece en su catálogo de derechos básicos la garantía en comento, sí introduce en nuestro país la institución de la Asociación de Consumidores, entendida como: 
[Aquella] organización constituida por personas naturales o jurídicas, independientes de todo interés económico, comercial o político, cuyo objetivo sea proteger, informar y educar a los consumidores y asumir la representación y defensa de los derechos de sus afiliados y de los consumidores que así lo soliciten, todo ello con independencia de cualquier otro interés (Art. 5 LPC).

Adicionalmente, cabe agregar que nuestra Carta Fundamental, en su Art. 1 inc. $2^{\circ}$ ya reconoce a los grupos intermedios - entre ellos, las asociaciones de consumidores - y les asegura la autonomía necesaria para cumplir sus propios fines específicos. ${ }^{38}$

Por último cabe señalar que la CPR, en su Art. 23 inc. $1^{\circ}$, establece que las organizaciones de este tipo que hagan mal uso de la autonomía antedicha, interviniendo de manera indebida en actividades ajenas a sus fines específicos, serán sancionadas de acuerdo a la Ley, ${ }^{39}$ regla que es replicada por el Art. 7 LPC. ${ }^{40}$

\section{RESPECTO DE LA NECESIDAD DE CONSAGRAR EXPRESAMENTE LAS garantías de los consumidores en la Constitución Política Chilena}

De acuerdo a lo señalado con anterioridad es que se puede sostener que nuestro sistema constitucional, si bien no contiene normas que tengan por objeto tutelar de manera exclusiva los derechos del sujeto más débil de la relación de consumo, sí contempla otras garantías que —al proteger a la comunidad en general— producen el mismo efecto.

Por otra parte, cabe señalar que, incluso si se quisiera incluir en la Constitución la protección de sujetos desfavorecidos, existen otros aún más vulnerables, que merecerían una protección constitucional previa. Es lo que ocurriría, por ejemplo, con los menores, los discapacitados y los adultos mayores.

Así las cosas, una eventual reforma constitucional que tenga por objeto incluir, dentro del texto de nuestra Carta Fundamental, la tutela de los consumidores de manera expresa, no solo resultaría injustificada, sino que además, podría generar efectos adversos para la economía nacional, al dar mayor rigidez — en ocasiones, de forma inconveniente - tanto a nuestro sistema económico como a la propia protección de los usuarios.

\section{Conclusión}

a) El Derecho Comparado sí ha consagrado la protección constitucional de los derechos de los consumidores, particularmente mediante la utilización de dos técnicas normativas: mencionar las garantías de los usuarios como derechos fundamentales o bien incluir su tutela a propósito del sistema económico. 
b) La Constitución Política de la República de Chile no consagra de manera expresa los derechos de los consumidores, sin perjuicio de que sus garantías básicas sí sean posibles de desprender del Catálogo de Derechos Fundamentales que ella contiene.

c) En nuestro país se han presentado dos propuestas de reforma constitucional que han pretendido incorporar la tutela constitucional de los consumidores, ninguna de las cuales, hasta el momento, ha devenido en normativa vigente.

d) El Estado Social y Democrático de Derecho se manifiesta y concretiza en la protección del sujeto más débil de la relación de consumo.

e) No resulta necesaria una protección constitucional expresa de los derechos de los consumidores, por cuanto ella ya se desprende de las disposiciones de nuestra Carta Fundamental.

\section{NOTAS}

1 “Se denomina 'constitucionalización' al proceso y al resultado de la transformación del Derecho causada por la Constitución” (apud CARBONELL, 2003, p. 163).

2 "El concepto de constitucionalización, como yo lo entiendo, no es un concepto bipolar (verdadero o falso), de forma que un ordenamiento únicamente pueda estar constitucionalizado o no estarlo en absoluto, sin algún punto intermedio. Más bien sostengo que la constitucionalización es una cuestión de grado, en el sentido de que un ordenamiento puede estar más o menos constitucionalizado. Y esto depende de cuántas y cuáles condiciones de constitucionalización estén satisfechas en el seno de aquel ordenamiento" (GUASTINI, 2003, p. 50).

3 De acuerdo con Guastini (2003, p. 50 y ss.), son condiciones de constitucionalización las siguientes: la existencia de una Constitución rígida; la garantía jurisdiccional de la Constitución; la fuerza vinculante de la Constitución; la sobreinterpretación de la Constitución; la aplicación directa de las normas constitucionales; la interpretación de las leyes de acuerdo a la Constitución; y la influencia de la Constitución sobre las relaciones políticas.

4 El llamado constitucionalismo fuerte o liberal —a diferencia del clásico-, según Comanducci (apud CARBONELL, 2003, p. 77), es aquel que no sólo limita el poder político, sino que, además, establece los derechos fundamentales del hombre.

5 Se entiende por Derecho Constitucional Dogmático: "Aquella parte o sector del ordenamiento constitucional referido a la dignidad humana, los derechos fundamentales y sus garantías, como asimismo, a los deberes constitucionales asignadores de tareas del Estado en favor de la persona” (CELIS DANZINGER, 2011, p. 119).

6 Estos derechos surgen a partir de las Revoluciones Liberales — principalmente, la francesa- a modo de rebelión en contra del orden político imperante. Se trata de garantías que imponen al Estado un deber de respeto. Entre ellas encontramos el derecho a la vida, a la libertad, a la igualdad, al voto, a ser electo, etc. 
7 Estos derechos surgen, en general, a partir de la Revolución Industrial e imponen al Estado una obligación de hacer, esto es, de proporcionar su satisfacción mediante el establecimiento de un sistema asistencialista. Son ejemplos de estas garantías: el derecho al trabajo, a un salario justo, a la libre asociación, a la seguridad social, a la cultura, etc.

8 Estos derechos surgen con posterioridad a la Segunda Guerra Mundial, como resultado de la integración recíproca de las naciones y de los grupos que las componen. Se trata de garantías que imponen al Estado obligaciones tanto de hacer como de no hacer. Son ejemplos de ellas: el derecho a la paz, al medio ambiente, a la autodeterminación de los pueblos, a la tutela de grupos vulnerables, etc.

9 Asimismo, se ha señalado que se trata de derechos que presentan algunos rasgos comunes, a saber: no son derechos declarados 'frente al Estado', sino que aparecen también en las relaciones entre particulares; los valores puestos de resalto son la solidaridad y la cooperación; el interés jurídicamente protegido se vincula con necesidades comunes a conjuntos indeterminados de individuos, que sólo pueden ser satisfechas desde una óptima comunitaria; se trata, pues, de 'intereses difusos', que reposan en circunstancias puramente fácticas, frecuentemente genéricas, contingentes y mutables; la preocupación por su defensa es compartida por los Derechos Público y Privado, de manera que puede producirse una ‘publicización’ del Derecho Privado o una 'privatización’ del Derecho Público; sus 'enemigos' son, en muchas ocasiones, titulares de poderes aún más fuertes que el mismo Estado, tales como personas físicas o jurídicas en situación 'de dominación, etc. (HUENCHIMAN, 2004, p. 58 y 59).

10 De acuerdo a Cea Egaña, consiste en: "La incorporación de ese reconocimiento y promoción a los tratados internacionales, sean de alcance universal o regional, configurándose así el Derecho Constitucional internacional o supranacional" (2004, p. 68).

11 Florianópolis, Brasil, 15/12/2000, suscrita por Argentina, Brasil, Uruguay y Paraguay.

12 En general las legislaciones han consagrado ciertos derechos de los consumidores, a los cuales han otorgado el calificativo de "básicos". En general, se consagran en la parte preliminar de las leyes de protección de los derechos de los consumidores y provienen, principalmente, del discurso pronunciado por el presidente John Kennedy el día 15 de marzo de 1962 ante el Congreso de Estados Unidos. La importancia de que una garantía sea calificada o no como básica radica en los efectos jurídicos que se derivan de uno u otro caso. En efecto, mientras la doctrina atribuye al consumidor abstracto - todos los ciudadanos, en cuanto personas - los derechos básicos, al consumidor concreto - aquel que efectivamente ha intervenido con el proveedor en un caso particular - se le conceden, de manera adicional, otras prerrogativas, entre las cuales se encuentran las acciones contractuales, la garantía legal, el derecho a retracto, etc. (JARA AMIGO, 1999, p. 62). En nuestro país, los derechos básicos se encuentran consagrados en la primera parte del Art. 3 LPC, que reza: "Son derechos y deberes básicos del consumidor: a) La libre elección del bien o servicio. El silencio no constituye aceptación en los actos de consumo. b) El derecho a una información veraz y oportuna sobre los bienes y servicios ofrecidos, su precio, condiciones de contratación y otras características relevantes de los mismos, y el deber de informarse responsablemente de ellos; c) El no ser discriminado arbitrariamente por parte de proveedores de bienes y servicios; d) La seguridad en el consumo de bienes o servicios, la protección de la salud y el medio ambiente y el deber de evitar los riesgos que puedan afectarles; e) El derecho a la reparación e indemnización adecuada y oportuna de todos los daños materiales y morales en caso de incumplimiento de cualquiera de las obligaciones contraídas por el proveedor y el deber de accionar de acuerdo a los medios que la ley le franquea, y f) La educación para un consumo responsable, y el deber de celebrar operaciones de consumo con el comercio establecido". En derecho comparado, en general, se agrega el derecho a la protección de los intereses económicos.

13 Art. 42 Constitución Política de la Nación Argentina: "Los consumidores y usuarios de bienes y servicios tienen derecho, en la relación de consumo, a la protección de su salud, seguridad e intereses económicos; a una información adecuada y veraz; a la libertad de elección, y a condiciones de trato equitativo y digno. / Las autoridades proveerán a la protección de esos derechos, a la educación para el consumo, a la defensa de la competencia contra toda forma de distorsión de los mercados, al control de los monopolios naturales y legales, al de la calidad y eficiencia de los servicios públicos, y a la constitución de asociaciones de consumidores y de usuarios. / La legislación establecerá procedimientos eficaces para la prevención y solución de conflictos, y los marcos regulatorios de los servicios públicos de competencia nacional, previendo la necesaria participación de las asociaciones de consumidores y usuarios y de las provincias interesadas, en los organismos de control”.

14 Art. 43 Constitución Política de la Nación Argentina: “Toda persona puede interponer acción expedita y rápida de amparo, siempre que no exista otro medio judicial más idóneo, contra todo acto u omisión de autoridades públicas o 
de particulares, que en forma actual o inminente lesione, restrinja, altere o amenace, con arbitrariedad o ilegalidad manifiesta, derechos y garantías reconocidos por esta Constitución, un tratado o una ley. En el caso, el juez podrá declarar la inconstitucionalidad de la norma en que se funde el acto u omisión lesiva. / Podrán interponer esta acción contra cualquier forma de discriminación y en lo relativo a los derechos que protegen al ambiente, a la competencia, al usuario y al consumidor, así como a los derechos de incidencia colectiva en general, el afectado, el defensor del pueblo y las asociaciones que propendan a esos fines, registradas conforme a la ley, la que determinará los requisitos y formas de su organización. / Toda persona podrá interponer esta acción para tomar conocimiento de los datos a ella referidos y de su finalidad, que consten en registros o bancos de datos públicos, o los privados destinados a proveer informes, y en caso de falsedad o discriminación, para exigir la supresión, rectificación, confidencialidad o actualización de aquéllos. No podrá afectarse el secreto de las fuentes de información periodística. / Cuando el derecho lesionado, restringido, alterado o amenazado fuera la libertad física, o en caso de agravamiento ilegítimo en la forma o condiciones de detención, o en el de desaparición forzada de personas, la acción de hábeas corpus podrá ser interpuesta por el afectado o por cualquiera en su favor y el juez resolverá de inmediato, aún durante la vigencia del estado de sitio".

15 Art. 20 CPE Bolivia: "I. Toda persona tiene derecho al acceso universal y equitativo a los servicios básicos de agua potable, alcantarillado, electricidad, gas domiciliario, telecomunicaciones y transporte. II. Es responsabilidad del Estado, en todos sus niveles de gobierno, la provisión de los servicios básicos a través de entidades públicas, autárquicas, mixtas, cooperativas o comunitarias. La provisión de servicios debe responder a los criterios de universalidad, responsabilidad, accesibilidad, continuidad, calidad, eficiencia, eficacia, tarifas equitativas y cobertura necesaria; con participación y control social. III. Los servicios básicos no serán objeto de concesión ni privatización”.

16 Constitución Política del Estado de Bolivia: Art. 75 "Las usuarias y los usuarios y las consumidoras y los consumidores gozan de los siguientes derechos: 1. Al suministro de alimentos, fármacos y productos en general, en condiciones de inocuidad, calidad, y cantidad disponible adecuada y suficiente, con prestación eficiente y oportuna del suministro. 2. A la información fidedigna sobre las características y contenidos de los productos que consuman y servicios que utilicen”; Art. 76: "I. El Estado garantiza el acceso a un sistema de transporte integral en sus diversas modalidades. La ley determinará que el sistema de transporte sea eficiente y eficaz, y que genere beneficios a los usuarios y a los proveedores”.

17 Constitución Política de la República de Ecuador: Art. 52 "Las personas tienen derecho a disponer de bienes y servicios de óptima calidad y a elegirlos con libertad, así como a una información precisa y no engañosa sobre su contenido y características. / La ley establecerá los mecanismos de control de calidad y los procedimientos de defensa de las consumidoras y consumidores; y las sanciones por vulneración de estos derechos, la reparación e indemnización por deficiencias, daños o mala calidad de bienes y servicios, y por la interrupción de los servicios públicos que no fuera ocasionada por caso fortuito o fuerza mayor"; Art. 53: "Las empresas, instituciones y organismos que presten servicios públicos deberán incorporar sistemas de medición de satisfacción de las personas usuarias y consumidoras, y poner en práctica sistemas de atención y reparación. / El Estado responderá civilmente por los daños y perjuicios causados a las personas por negligencia y descuido en la atención de los servicios públicos que estén a su cargo, y por la carencia de servicios que hayan sido pagados"; Art. 54: "Las personas o entidades que presten servicios públicos o que produzcan o comercialicen bienes de consumo, serán responsables civil y penalmente por la deficiente prestación del servicio, por la calidad defectuosa del producto, o cuando sus condiciones no estén de acuerdo con la publicidad efectuada o con la descripción que incorpore. / Las personas serán responsables por la mala práctica en el ejercicio de su profesión, arte u oficio, en especial aquella que ponga en riesgo la integridad o la vida de las personas"; Art. 55: "Las personas usuarias y consumidoras podrán constituir asociaciones que promuevan la información y educación sobre sus derechos, y las representen y defiendan ante las autoridades judiciales o administrativas. / Para el ejercicio de este u otros derechos, nadie será obligado a asociarse”.

18 Art. 51 Constitución Española: “1. Los poderes públicos garantizarán la defensa de los consumidores y usuarios, protegiendo, mediante procedimientos eficaces, la seguridad, la salud y los legítimos intereses económicos de los mismos. / 2. Los poderes públicos promoverán la información y la educación de los consumidores y usuarios, fomentarán sus organizaciones y oirán a éstas en las cuestiones que puedan afectar a aquéllos, en los términos que la ley establezca. / 3. En el marco de lo dispuesto por los apartados anteriores, la ley regulará el comercio interior y el régimen de autorización de productos comerciales".

19 Art. 5. ${ }^{\circ}$ Constitución de la República Federal de Brasil: “Todos são iguais perante a lei, sem distinção de qualquer natureza, garantindo-se aos brasileiros e aos estrangeiros residentes no País a inviolabilidade do direito à vida, à liberdade, à igualdade, à segurança e à propriedade, nos termos seguintes: XXXII - o Estado promoverá, na forma da lei, a defesa do consumidor". 
20 Art. 65 Constitución Política peruana: "Protección al consumidor. El Estado defiende el interés de los consumidores y usuarios. Para tal efecto garantiza el derecho a la información sobre los bienes y servicios que se encuentran a su disposición en el mercado. Asimismo vela, en particular, por la salud y la seguridad de la población”.

21 Art. 81 Constitución de la República Portuguesa: "Incumbe prioritariamente ao Estado no âmbito económico e social: a) Promover o aumento do bem-estar social e económico e da qualidade de vida das pessoas, em especial das mais desfavorecidas, no quadro de uma estratégia de desenvolvimento sustentável; b) Promover a justiça social, assegurar a igualdade de oportunidades e operar as necessárias correcções das desigualdades na distribuição da riqueza e do rendimento, nomeadamente através da política fiscal; c) Assegurar a plena utilização das forças produtivas, designadamente zelando pela eficiência do sector público; d) Promover a coesão económica e social de todo o território nacional, orientando o desenvolvimento no sentido de um crescimento equilibrado de todos os sectores e regiões e eliminando progressivamente as diferenças económicas e sociais entre a cidade e o campo e entre o litoral e o interior; e) Promover a correcção das desigualdades derivadas da insularidade das regiões autónomas e incentivar a sua progressiva integração em espaços económicos mais vastos, no âmbito nacional ou internacional; f) Assegurar o funcionamento eficiente dos mercados, de modo a garantir a equilibrada concorrência entre as empresas, a contrariar as formas de organização monopolistas e a reprimir os abusos de posição dominante e outras práticas lesivas do interesse geral; g) Desenvolver as relações económicas com todos os povos, salvaguardando sempre a independência nacional e os interesses dos portugueses e da economia do país; h) Eliminar os latifúndios e reordenar o minifúndio; i) Garantir a defesa dos interesses e os direitos dos consumidores; j) Criar os instrumentos jurídicos e técnicos necessários ao planeamento democrático do desenvolvimento económico e social; l) Assegurar uma política científica e tecnológica favorável ao desenvolvimento do país; m) Adoptar uma política nacional de energia, com preservação dos recursos naturais e do equilíbrio ecológico, promovendo, neste domínio, a cooperação internacional; n) Adoptar uma política nacional da água, com aproveitamento, planeamento e gestão racional dos recursos hídricos".

22 Moción de los diputados señores Burgos, Saffirio, Silva, Tuma, Ascencio y Mella, sobre Reconocimiento constitucional de la libre competencia y de los derechos de los consumidores, Boletín No 2.963-07, junio de 2002.

23 Moción de los senadores Espina, Chadwick, García, Tuma y Zaldívar, sobre reforma constitucional, Boletín $\mathrm{N}^{\circ}$ 7.563-07, abril de 2011.

24 Art. 19 CPR: "La Constitución asegura a todas las personas: $N^{\circ}$ 21: El derecho a desarrollar cualquiera actividad económica que no sea contraria a la moral, al orden público o a la seguridad nacional, respetando las normas legales que la regulen”.

25 A lo anterior habría que agregar que, según el profesor Cea Egaña, el catálogo de garantías contemplado en el Art. $19 \mathrm{CPR}$ no tendría el carácter de taxativo, de tal manera que sería posible que nuestro ordenamiento jurídico reconociese otros derechos fundamentales que generen los mismos efectos jurídicos. Señala los siguientes argumentos: a) La enumeración del Art. 19 sería abierta, puesto que existirían otras disposiciones —incluso constitucionales - que consagran garantías esenciales. Es lo que ocurriría por ejemplo, con la nacionalidad; b) De acuerdo a la historia fidedigna, se puede desprender que el constituyente reconocía la existencia de otros derechos no contemplados en el Art. 19, en la medida que provengan de la dignidad humana; c) Existen numerosos tratados internacionales que incorporan derechos humanos a nuestro sistema jurídico. En el mismo sentido, señala: "La Declaración de Derechos contenida en el Capítulo III es la más larga y completa de todas las contempladas en las Constituciones chilenas. Sin embargo, esa evolución y enriquecimiento no significan que sea un catálogo cerrado o taxativo, es decir, que no puedan incluirse otros derechos en él, como si fuera razonable propugnar la clausura del progreso humano" (CEA EGAÑA apud PEÑA GONZÁLEZ, 1996, p. 32).

26 Otro concepto: "Cuyo Derecho da a la comunidad política un contenido y una estructura específica" (SANTOS BALLESTEROS, 1973, p. 26).

27 Mensaje de Proyecto $N^{\circ} 187-322,19.08 .1991$.

28 Art. 1 inc. $3^{\circ} \mathrm{CPR}$ : "El Estado está al servicio de la persona humana y su finalidad es promover el bien común, para lo cual debe contribuir a crear las condiciones sociales que permitan a todos y a cada uno de los integrantes de la comunidad nacional su mayor realización espiritual y material posible, con pleno respeto a los derechos y garantías que esta Constitución establece”.

29 Art. 1 inc. $4^{\circ} \mathrm{CPR}$ : "Es deber del Estado resguardar la seguridad nacional, dar protección a la población y a la 
familia, propender al fortalecimiento de ésta, promover la integración armónica de todos los sectores de la Nación y asegurar el derecho de las personas a participar con igualdad de oportunidades en la vida nacional”.

30 Art. 19 CPR: "La Constitución asegura a todas las personas: $\mathrm{N}^{\circ}$ 8: El derecho a vivir en un medio ambiente libre de contaminación. Es deber del Estado velar para que este derecho no sea afectado y tutelar la preservación de la naturaleza. / La ley podrá establecer restricciones específicas al ejercicio de determinados derechos o libertades para proteger el medio ambiente”.

31 Art. 1 inc. $1^{\circ}$ CPR: "Las personas nacen libres e iguales en dignidad y derechos".

32 CPR: Art. 19: "La Constitución asegura a todas las personas: $2^{\circ}$.- La igualdad ante la ley. En Chile no hay persona ni grupo privilegiados. En Chile no hay esclavos y el que pise su territorio queda libre. Hombres y mujeres son iguales ante la ley. Ni la ley ni autoridad alguna podrán establecer diferencias arbitrarias; $\mathrm{N}^{\circ} 3^{\circ}$.- La igual protección de la ley en el ejercicio de sus derechos [...]".

33 Art. $19 \mathrm{~N}^{\circ} 10 \mathrm{CPR}$ : “[...] Corresponderá al Estado, asimismo, fomentar el desarrollo de la educación en todos sus niveles".

34 Fernández Fredes: “[A] diferencia del derecho a la información básica comercial, el de ser educado en materia de consumo no tiene como sujeto pasivo [...] al proveedor mismo, sino al Estado, que lo satisface a través del organismo oficial especializado en la materia — el Servicio Nacional del Consumidor - y también por medio del sistema educativo general" (1998, p. 118).

35 CPR: Art. 19: "La Constitución asegura a todas las personas: $\mathrm{N}^{\circ} 24$ inc. 1: El derecho de propiedad en sus diversas especies sobre toda clase de bienes corporales o incorporales".

36 Se trata de una norma novedosa en nuestro sistema jurídico, puesto que — a diferencia del Derecho Comúnviene a explicitar el resarcimiento del daño extrapatrimonial, a la manera de otras legislaciones comparadas. En este último sentido: Art. 6 Ley de relaciones de consumo, Uruguay: "Son derechos básicos de los consumidores: [...] f) La efectiva prevención y resarcimiento de los daños patrimoniales y extrapatrimoniales".

37 “Sernac con Braún Medical S.A.”, Rol 3422-4-2008, JPL San Bernardo, 18.01.2010, Considerando 48, confirmada por la C. Ap. San Miguel, Ing. 187-2010, 17.05.2010. En el mismo sentido, se pronunció el Tercer Juzgado de Letras de Antofagasta: "En lo que dice relación con el daño moral, éste [...] posee una manifestación positiva en la normativa suprema de la Constitución Política de la República, cuyo artículo 19, en su numeral primero, asegura el derecho a la integridad física y psíquica, y el numeral $4^{\circ}$ consagra el respeto y protección a la vida privada y pública y a la honra de la persona y su familia. Bienes de excelencia e ideales por naturaleza que, al amparo del reconocimiento constitucional, deben recibir de parte de los órganos encargados de hacer operante el ordenamiento jurídico, que arranca su origen y validez en la Carta Fundamental, amplio resguardo y protección, incluido el resarcimiento pecuniario, cuando resultan afectados por actos que los lesionan o menoscaban", "Stjepovich González con Universidad de Antofagasta”, Rol 36.4922001, 3 J.L. Antofagasta, 24.05.2002, confirmada por la C. Ap. De Antofagasta, 11.12.2002, se acoge recurso de casación, C.S., Ing. 228-2003, 09.11.2004.

38 Art. 1 inc. $2^{\circ} \mathrm{CPR}$ : "El Estado reconoce y ampara a los grupos intermedios a través de los cuales se organiza y estructura la sociedad y les garantiza la adecuada autonomía para cumplir sus propios fines específicos”.

39 Art. 23 inc. 1 CPR: "Los grupos intermedios de la comunidad y sus dirigentes que hagan mal uso de la autonomía que la Constitución les reconoce, interviniendo indebidamente en actividades ajenas a sus fines específicos, serán sancionados en conformidad a la ley".

40 Art. 7 LPC: “Además de las causales de disolución indicadas en el artículo 18 del decreto ley $\mathrm{N}^{\circ}$ 2.757, de 1979, las organizaciones de consumidores pueden ser disueltas por sentencia judicial o por disposición de la ley, a pesar de la voluntad de sus miembros. / En caso de que el juez, dentro del plazo de tres años, declare temerarias dos o más demandas colectivas interpuestas por una misma Asociación de Consumidores, podrá, a petición de parte, en casos graves y calificados, decretar la disolución de la asociación, por sentencia fundada. / Los directores de las Asociaciones de Consumidores disueltas por sentencia judicial quedarán inhabilitados para formar parte, en calidad de tales, de otras asociaciones de consumidores, durante el período de dos años”. 


\section{REFERENCIAS}

Doctrina y artículos de opinión

CARBONELL, Miguel. "La libertad de asociación y de reunión en México". Anuario de Derecho Constitucional Latinoamericano, 2006.

CEA EGAÑA, José Luis. "Dignidad, derechos y garantías en el régimen constitucional chileno”. PEÑA GONZÁLEZ, Carlos. Práctica constitucional y derechos fundamentales. Santiago: Editorial Corporación Nacional de Reparación y Reconciliación, 1996.

Derecho constitucional chileno. Santiago: Ediciones Universidad Católica de Chile, 2004, tomo 2.

CELIS DANZINGER, Gabriel Enrique. Curso de derecho constitucional. Santiago: Editorial Thomson Reuters, 2011. COMANDUCCI, Paolo. "Formas de (neo)constitucionalismo: un análisis metateórico". In: CARBONELL, Miguel Ed. Neconstitucionalismo(s). Madrid: Editorial Trotta, 2003.

FERNÁNDEZ FREDES, Francisco. "Nueva Ley del Consumidor: innovaciones y limitaciones". Revista Perspectivas en Política, Economía y Gestión, Faculta de Ingeniería y Ciencias Universidad de Chile, vol. 1, n 2, Santiago, 1998. . Manual de derecho de protección al consumidor. Santiago: Editorial Lexis Nexis, 2003.

FERNÁNDEZ SESSAREGO, Carlos. Abuso del derecho. Buenos Aires: Editorial Astrea, 1992.

GARCÍA FIGUEROA, Alfonso. "La teoría del derecho en tiempos de constitucionalismo". In: CARBONELL, Miguel Ed. Neconstitucionalismo(s). Madrid: Editorial Trotta, 2003.

GUASTINI, Riccardo. “La 'constitucionalización' del ordenamiento jurídico: El caso italiano”. In: CARBONELL, Miguel Ed. Neconstitucionalismo(s). Madrid: Editorial Trotta, 2003.

HESSE, Conrado. "Constitución y derecho constitucional”. In: BENDA, Ernesto et al. Manual de derecho constitucional. 2. ed. Madrid: Editorial Marcial Pons, 2001.

HUENCHIMAN, Valeria. "La Constitución Nacional, el consumidor y el usuario". In: STIGLITZ, Gabriel A. Manual de defensa del consumidor. Rosario: Editorial Juris, 2004.

JARA AMIGO, Rony. "Ámbito de aplicación de la Ley chilena de protección al consumidor: inclusiones y exclusiones”. In: CORRAL TALCIANI, Hernán (ed.). "Derecho del consumo y protección al consumidor”. Cuadernos de Extensión n ${ }^{\circ}$ 3, Santiago: Facultad de Derecho, Universidad de Los Andes, 1999.

MEDINA Q., Cecilia; ZALAQUETT D., José. “Prólogo”. Derechos Humanos hoy, Balance internacional. Santiago: Editorial Catalonia, Facultad de Derecho de la Universidad de Chile, Centro de Derechos Humanos, 2008. PERRET, Louis. "Protección al consumidor: en Canadá y Estados Unidos: principales técnicas". In: CORRAL TALCIANI, Hernán (ed.). Derecho del consumo y protección al consumidor. Cuadernos de Extensión n ${ }^{\circ}$, Santiago: Facultad de Derecho, Universidad de Los Andes, 1999.

RODRÍGUEZ LLAMAS, Sonia. Régimen de responsabilidad civil por productos defectuosos. Navarra: Editorial Aranzadi, 2002.

SANTOS BALLESTEROS, Jorge. El abuso del Derecho. Bogotá: Editorial Universidad Javeriana, 1973.

VALADÉS, Diego. "La no aplicación de las normas y el Estado de Derecho". Boletín Mexicano de Derecho Comparado, $\mathrm{n}^{\circ} 103,2002$.

Normativa e instrumentos internacionales

Constitución Política de la República de Chile.

Constitución Política de la Nación Argentina.

Constitución Política del Estado de Bolivia.

Constitución Política de la República de Ecuador.

Constitución Española.

Constitución de la República Federal de Brasil.

Constitución Política de Perú.

Constitución de la República Portuguesa.

“Declaración presidencial de Derechos Fundamentales de los Consumidores del Mercosur”, Florianópolis, Brasil, 15.12.2000.

Ley 19.496, Chile.

Ley de relaciones de consumo, Uruguay.

Jurisprudencia

"Sernac con Braún Medical S.A.”, Rol 3422-4-2008, JPL San Bernardo, 18.01.2010, confirmada por la C. Ap. San Miguel, Ing. 187-2010, 17.05.2010.

“Stjepovich González con Universidad de Antofagasta”, Rol 36.492-2001, 3 J.L. Antofagasta, 24.05.2002, confirmada por la C. Ap. De Antofagasta, 11.12.2002, se acoge recurso de casación, C.S., Ing. 228-2003, 09.11.2004. 


\section{Proyectos normativos}

Mensaje de Proyecto N 187-322, 19.08.1991.

Moción de los diputados señores Burgos, Saffirio, Silva, Tuma, Ascencio y Mella, sobre Reconocimiento constitucional de la libre competencia y de los derechos de los consumidores, Boletín N ${ }^{\circ}$ 2.963-07, junio de 2002. Moción de los senadores Espina, Chadwick, García, Tuma y Zaldívar, sobre reforma constitucional, Boletín $\mathrm{N}^{\circ}$ 7.563-07, abril de 2011.

Erika M. Isler Soto

erikaislerlayahoo.es |

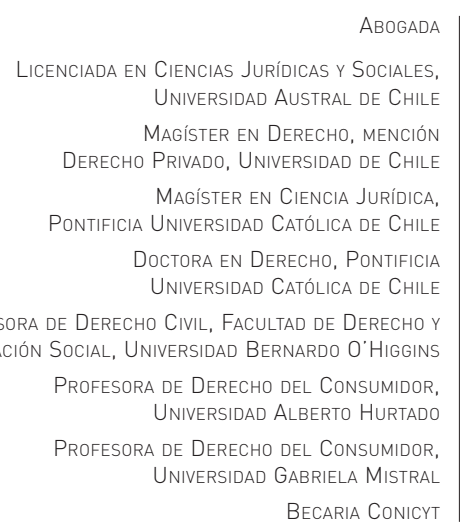

